\section{BRAZIULIAN JOURNAL}

OF MEDICAL AND BIOLOGICAL RESHARCH

www.bjournal.com.br
ISSN 0100-879X

Volume 43 (03) 226-324 March 2010

BIOMEDICAL SCIENCES

AND

CLINICAL INVESTIGATION

Braz J Med Biol Res, March 2010, Volume 43(3) 290-296

\title{
Human umbilical cord blood cells in infarcted rats
}

V. Pinho-Ribeiro, A.C.V. Maia, J.P.S. Werneck-de-Castro, P.F. Oliveira, R.C.S. Goldenberg and A.C. Campos de Carvalho

The Brazilian Journal of Medical and Biological Research is partially financed by
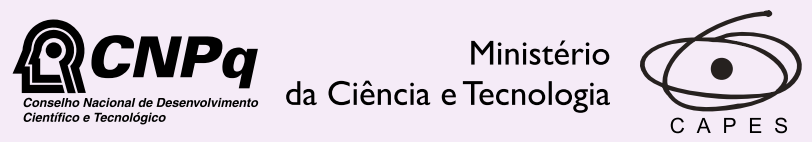

Ministério da Educação

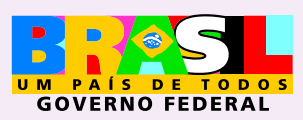

Institutional Sponsors

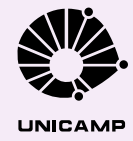




\title{
Human umbilical cord blood cells in infarcted rats
}

\author{
V. Pinho-Ribeiro ${ }^{1}$, A.C.V. Maia1 ${ }^{1}$, J.P.S. Werneck-de-Castro' ${ }^{1,2}$, P.F. Oliveira1,3, \\ R.C.S. Goldenberg ${ }^{1}$ and A.C. Campos de Carvalho ${ }^{1,4}$ \\ ${ }^{1}$ Instituto de Biofísica Carlos Chagas Filho, ${ }^{2}$ Laboratório de Biologia Muscular e do Exercício, \\ Departamento de Biociências e Atividade Física, EEFD, \\ Universidade Federal do Rio de Janeiro, Rio de Janeiro, RJ, Brasil \\ 3 Área de Ciências Fisiológicas, Instituto de Ciências Biomédicas, \\ Universidade Federal de Uberlândia, Uberlândia, MG, Brasil \\ ${ }^{4}$ Albert Einstein College of Medicine, New York, NY, USA
}

\begin{abstract}
Therapy with bone marrow-derived cells has been used in ischemic patients with reported success. The aim of this study was to determine the therapeutic efficacy of fresh and frozen human umbilical cord blood cells (hUCB) in Wistar rats submitted to permanent occlusion of the left coronary artery. Three hours after myocardial infarction, $2 \times 10^{7} \mathrm{hUCB}$ cells or vehicle were administered by intramyocardial injection. The animals were divided into five groups: control $(N=10)$, sham operated $(N=10)$, infarcted that received vehicle $(N=9)$, infarcted treated with cryopreserved hUCB $(N=7)$, and infarcted treated with fresh hUCB $(\mathrm{N}=5)$. Cardiac function was evaluated by electrocardiogram (ECG) and echocardiogram (ECHO) before cell therapy, and by ECG, ECHO, cardiopulmonary test, and left ventricular pressure measurements 3 weeks later. After 3 weeks, both groups treated with hUCB still had $\mathrm{Q}$ wave present in L1, âQRS $>90^{\circ}$ and reduced shortening fraction (less than $50 \%$ ). In addition, cardiac indexes of left ventricular contractility and relaxation were $5484 \pm 875$ and $-4032 \pm 643 \mathrm{mmHg}$ (cryopreserved hUCB) and $4585 \pm 955$ and $-2862 \pm 590 \mathrm{mmHg}$ (fresh hUCB), respectively. These values were not statistically different from those of saline-treated animals. Cardiopulmonary exercise test profile was typical of infarcted hearts; exercise time was about 14 min and maximal $\mathrm{VO}_{2}$ was $24.77 \pm 5.00 \mathrm{~mL} \cdot \mathrm{kg}^{-1} \cdot \mathrm{min}^{-1}$. These data show that hUCB therapy did not improve the cardiac function of infarcted animals or prevent cardiac remodeling.
\end{abstract}

Key words: Cell therapy; Fresh and frozen human umbilical cord blood; Acute myocardial infarction; Electrocardiogram; Echocardiogram

\section{Introduction}

Myocardial infarction (MI) leads to myocyte death causing progressive structural and functional changes in the heart. This cardiac remodeling contributes to abnormal left ventricle (LV) function and to the development of heart failure (1). In most patients, pharmacological therapies are successful in slowing the development of heart failure but in some the disease progresses in spite of drug therapy and the only therapeutic option is cardiac transplantation (2). However, the search for compatible donors and immune suppression limit the application of this procedure and alternative therapies are needed. For these reasons, cell therapy has become a novel option for patients with ischemic heart disease.

Cell transplantation has been investigated intensively in the setting of MI. Many cell types such as fetal cardiomyocytes, embryonic stem cells, skeletal myoblasts, and bone marrow stem cells have been evaluated in animal models (for a review, see Ref. 3). Skeletal myoblasts and bone marrow-derived cells have been the cell types most frequently used for the treatment of myocardial infarction because of their autologous nature, easy availability and the lack of specific ethical questions about their use in medicine. However, neither cell type is ideal for therapy. Skeletal myoblasts do not express connexin 43 (4) and may cause arrhythmias when transplanted (5). Bone marrowderived cells, on the other hand, do express connexin 43 and have not been reported to induce arrhythmias. However, Heeschen et al. (6) demonstrated that bone marrow mono-

Correspondence: A.C. Campos de Carvalho, Instituto de Biofísica Carlos Chagas Filho, CCS, Bloco G, UFRJ, 21941-902 Rio de Janeiro, RJ, Brasil. Fax: +55-21-2280-8193. E-mail: acarlos@biof.ufrj.br

Received March 11, 2009. Accepted January 26, 2010. Available online February 5, 2010. Published March 12, 2010. 
nuclear cells isolated from patients with chronic ischemic cardiomyopathy have reduced functional capacity and migratory response to stromal-derived factor 1 , which can limit the regenerating potential of these cells. Furthermore, these cells have been reported to decrease in numbers and viability with age (7).

On the basis of the limitations of these two cell types, the search for a more suitable cell has led investigators to study the repair potential of cord blood-derived cells in acute MI. Henning et al. $(8,9)$ and Wu et al. (10) reported that human umbilical cord blood (hUCB)-derived cells injected directly into the myocardium were effective in reducing infarct size and improving ventricular function in non-immunosuppressed rats. Further beneficial effects of cord blood cell therapy after acute $\mathrm{MI}$ in immunosuppressed animals have been reported (11-13). Hirata et al. (11) reported that transplantation of hUCB-derived CD $34^{+}$cells significantly improved ventricular function in infarcted animals. These cells were also reported to be able to migrate to the infarcted myocardium, engrafting and participating in neoangiogenesis, and thus beneficially influencing the remodeling process (12). Moreover, intravenous delivery of hUCB-derived CD $133^{+}$cells was reported to produce functional recovery by preventing scar thinning and LV systolic dilatation (13). In all studies in which the mononuclear fraction of hUCB was used, the cells were obtained from cryopreserved material. When specific cell types derived from hUCB were used (mesenchymal, CD $133^{+}, \mathrm{CD}_{3}{ }^{+}$and unrestricted somatic stem cells), fresh cord blood was the source. However, there are no reports in the literature comparing the therapeutic potential of fresh and frozen mononuclear cord blood cells. Therefore, the aim of the present study was to investigate the efficacy of fresh and cryopreserved hUCB mononuclear cells for the treatment of acute $\mathrm{MI}$ in nonimmunosuppressed rats subject to permanent ligation of the left coronary artery.

\section{Material and Methods}

\section{Animals}

All procedures were performed in accordance with the Guide for the Care and Use of Laboratory Animals published by the USA National Institutes of Health (NIH Publication No. 85-23, revised 1996) as attested by the Animal Experimentation Ethics Committee of UFRJ.

Wistar rats $(200-250 \mathrm{~g})$ were housed at controlled temperature $\left(23^{\circ} \mathrm{C}\right)$ with daily exposure to a 12-h light-dark cycle (lights on from 8:00 am to 8:00 pm) and free access to water and standard rat chow. The animals were divided into five groups: control rats $(\mathrm{N}=10)$; sham-operated rats $(\mathrm{N}=10)$; infarcted but not treated rats (INT, which received vehicle only; $N=9$ ); infarcted rats treated with either fresh $(\mathrm{N}=5)$ or cryopreserved hUCB mononuclear cells by intramyocardial injection $(\mathrm{N}=7)$.

\section{Myocardial infarction}

MI was induced by left artery descendent ligation (14). Briefly, rats were anesthetized with halothane (Merck, Germany) and a small thoracotomy was made on the left side between the 5th and 6th ribs. After exposing the heart, the descending branches of the left coronary artery were permanently occluded with a 5-0 silk suture, and the chest was closed. Sham-operated animals underwent the same procedure but without coronary ligation.

\section{Cell preparation}

hUBC samples were collected from normal human fullterm pregnancies without concomitant infectious diseases after written parental informed consent and institutional approval by the UFRJ Review Board. Fresh hUCB were collected $24 \mathrm{~h}$ before intramyocardial administration and maintained at $4^{\circ} \mathrm{C}$. Cryopreserved hUCB samples were obtained from a cryopreservation UCB bank from cord that did not meet the minimum number of cells required for cryopreservation and would therefore be discarded. Samples were stored frozen for 1 month and then thawed at $37^{\circ} \mathrm{C}$ and used. The mononuclear fraction of hUCB was obtained by Ficoll gradient centrifugation (Ficoll-Paque Plus, 1077 $\mathrm{g} / \mathrm{mL}$ GE Healthcare, Sweden) after extensive washing in phosphate-buffered saline (PBS) with $5 \%$ fetal bovine serum (Life Technologies ${ }^{\circledR}$, USA) and centrifugations at $480 \mathrm{~g}$ for $7 \mathrm{~min}$. In some experiments the mononuclear cells were labeled with Hoechst 33342 (Sigma, USA). The cells were washed three times with PBS and the supernatant of the last wash was retrieved and incubated in vitro with cells in culture to ascertain that extruded dye would not label new cells. After isolation and Hoechst staining, cell viability was analyzed by Trypan blue exclusion and was $>95 \%$.

\section{Cell transplantation}

Three hours after coronary occlusion, animals were anesthetized and ECG and ECHO were performed to confirm infarction. The chest was immediately opened and $100 \mu \mathrm{L}$ saline containing $1 \times 10^{7}$ mononuclear hUCB was infused into the myocardium at one or two distinct points along the border of the infarction. The infarcted non-treated animals received the same volume of PBS.

\section{Electrocardiogram}

The animals were anesthetized with ketamine and xylazine (50 and $5 \mathrm{mg} / \mathrm{kg}$, respectively, ip). Rats were placed in the supine position and electrodes connected to surgical needles were inserted subcutaneously in order to record the classical six limb leads (L1, L2, L3, aVR, $a V L$, and aVF) as previously described (15). The angle of the left ventricular depolarization vector (âQRS) and the presence of $Q$ wave in $L 1$ were determined from recordings obtained at $50 \mathrm{~mm} / \mathrm{s}$ with a sensitivity of $20 \mathrm{~mm} / \mathrm{mV}$ (Cardimax FX-2111, Fukuda Denshi, Japan). âQRS data are reported as frequency of animals with âQRS larger 
than $90^{\circ}$ (right axis deviation) or between 0 and $90^{\circ}$ (normal axis). âQRS $>90^{\circ}$ and presence of $Q$ wave in $L 1$ were used as evidence of infarction (15). Parameters were evaluated $3 \mathrm{~h}$ after left artery descendent ligation and 3 weeks after cell or saline injection.

\section{Echocardiogram}

Echocardiographic examination was performed in a blind manner by the same echocardiographist according to American Society of Echocardiography (ASE) recommendations. We used an echocardiographic color system (Megas/Esaote, Italy) equipped with a 10-MHz electronicphased-array transducer. Short-axis two-dimensional views of the LV were taken at the level of the papillary muscles to obtain the M-mode recordings. LV end-diastolic dimensions (LVEDD), LV end-systolic dimensions (LVESD), shortening fraction [SF $=($ LVEDD - LVESD) $/$ LVEDD $) * 100]$ and ejection fraction [EF $=(\text { LVEDD })^{3}-(\text { LVESD })^{3} /(\text { LVEDD })^{3}$ *100] were measured. In order to estimate global LV function, we calculated LV diastolic and systolic area (LVDA and LVSA, respectively) to determine shortening fractional area [SFA $(\%)=($ LVDA - LVSA $) /$ LVDA *100]. Additionally, the total and the akinetic perimeters of the LV in systole (LVTP and LVAP, respectively) were determined in order to calculate percent LV akinesis [\%LVA = (LVAP / LVTP) *100] at the level of the papillary muscles.

\section{Cardiopulmonary test}

Three weeks after the surgical procedure, animals were weighed and their cardiac function was analyzed under physiological stress (exercise). The test was performed according to an established protocol (16). We evaluated the maximal duration of running endurance by the animals and their maximal oxygen consumption ( $\left.\mathrm{VO}_{2} \mathrm{max}\right)$. In brief, after an adaptation period of 3 days, the animals started to run in a treadmill with a constant slope of $10^{\circ}$ at a velocity of $17 \mathrm{~cm} / \mathrm{s}$. The velocity was increased every 2 min by 2 $\mathrm{cm} / \mathrm{s}$ until exhaustion. Stainless steel grids provided an electrical shock to keep the animals running. Exhaustion was determined whenever the animal stayed on the steel grids for more than 1 min despite the shocks.

\section{Left ventricular pressure measurements in unanesthetized rats}

One day after the cardiopulmonary test, animals were anesthetized with ketamine/xylazine as described above, and the right carotid artery was cannulated with a PE10 catheter. One extremity of the catheter was inserted into the left ventricle and the opposite end was tunneled back and exposed between the scapulae. With the animal free to walk about in its cage $24 \mathrm{~h}$ after this procedure, the catheter was connected to a pressure transducer (MLT0380/D, ADInstruments, Australia) coupled to a Power Lab400 acquisition system (ADInstruments). After an adaptation period of $30 \mathrm{~min}$, LV pressure acquisition was started. The
LV parameters evaluated were: LV end-diastolic pressure (LVEDP), LV end-systolic pressure (LVESP), LV developed pressure $[($ LVDP $)=$ LVESP - LVEDP], cardiac index of LV contractility $(\mathrm{dP} / \mathrm{dT}+)$, and index of LV relaxation $(\mathrm{dP} /$ dT-). All data were measured using the Chart 4 software (PowerLab, ADInstruments).

\section{Histological procedures}

The animals were sacrificed following the LV pressure measurements. The hearts were excised, fixed with $4 \%$ paraformaldehyde and cut into three consecutive sections from base to apex of the LV: sections A, B, and C, respectively. Section $B$ contains the major portion of the LV infarcted region, in which the walls are macroscopically very thin. Samples from these regions were embedded in OCT (Tissue Tek), frozen at $-80^{\circ} \mathrm{C}$ and cut into 5 - $\mu \mathrm{m}$ thick sections. The sections were analyzed with an epifluorescence microscope (Axiovert 100, Carl Zeiss, Germany) to evaluate the presence of cells labeled with Hoechst 33342 (Sigma).

\section{Statistical analysis}

Data are reported as means \pm SD. Comparisons between two groups were made by the Student $t$-test. Differences between more than two groups were compared by oneway analysis of variance. Differences were considered to be significant when $\mathrm{P}<0.05$ after Bonferroni's correction.

\section{Results}

\section{Electrocardiographic analysis}

Three weeks after cell therapy, electrocardiographic parameters in the groups treated with fresh and cryopreserved hUCB cells were typical of infarcted animals. In other words, the $Q$ wave was present in $L 1$ and âQRS was $>90^{\circ}$ (Table 1). In contrast, in control and sham animals $Q$ wave was always absent in L1 and âQRS was $<90^{\circ}$. ECGs recorded $3 \mathrm{~h}$ after infarction surgery or 3 weeks after cell therapy were not significantly different between saline- and the two hUCB-treated groups. No significant difference in measured ECG parameters was observed between the two groups treated with fresh or cryopreserved hUCB.

\section{Echocardiographic analysis}

The two-dimension echocardiographic images taken at the level of the papillary muscle $3 \mathrm{~h}$ after infarction showed that the percentage of LV akinesis was $43.4 \pm 6.0 \%$ (INT); $47.10 \pm 9.2 \%$ (cryopreserved hUCB); $43.71 \pm 2.8 \%$ (fresh hUCB). These infarction sizes were not statistically different.

After 3 weeks, LVEDD and LVESD of the infarcted groups were significantly greater than those of the sham group $(P<0.001)$. In cryopreserved hUCB, LVEDD and LVESD were $8.9 \pm 0.60$ and $6.10 \pm 0.24 \mathrm{~mm}$, respectively, while in fresh hUCB these parameters were $10.0 \pm 0.20$ 
(LVEDD) and $8.9 \pm 0.60 \mathrm{~mm}$ (LVESD). Moreover, these parameters were significantly greater in both hUCB groups than in the INT group $(\mathrm{P}<0.05$; Table 2$)$. The ejection fraction was equally reduced in both infarcted groups treated with hUCB (cryopreserved hUCB $=48.60 \pm 10.47$ and fresh hUCB $=38.0 \pm 11.5 \%$ ) and both were significantly reduced in comparison with sham rats $(89.50 \pm 10.89 \%)$. This same pattern was observed in SF\% and SFA\%. In both groups treated with hUCB, SF\% was about $20 \%$. Again, no statistical difference in echocardiographic parameters was found between the fresh and cryopreserved hUCB groups.
Furthermore, echocardiographic parameters before and after hUCB treatment were not statistically different for both treatments.

\section{Left ventricular pressure measurements in unanesthetized rats}

LV pressure was measured in unanesthetized rats only 3 weeks after the surgical procedure. No statistical differences in LV pressure measurements $(\mathrm{dP} / \mathrm{dT}+, \mathrm{dP} /$ dT-, and LVDP) were observed between INT and the two hUCB-treated groups, as shown in Table 3. However, all

Table 1. Electrocardiographic parameters of control, sham-operated and infarcted rats 3 weeks after the surgical procedure.

\begin{tabular}{lccccc}
\hline Parameters & Control $(\mathrm{N}=10)$ & SO $(\mathrm{N}=9)$ & INT $(\mathrm{N}=9)$ & C-hUCB $(\mathrm{N}=7)$ & F-hUCB $(\mathrm{N}=5)$ \\
\hline Q wave in L1 & $\begin{array}{c}0 / 10 \\
\text { âQRS }\end{array}$ & $\begin{array}{c}0 / 9 \\
9 \text { left/0 right }\end{array}$ & $\begin{array}{c}9 / 9 \\
\text { a right }\end{array}$ & $\begin{array}{l}0 \text { left } / 9 \text { right } \\
\text { âleft } / 7 \text { right }\end{array}$ & $\begin{array}{c}5 / 5 \\
0 \text { left } / 5 \text { right }\end{array}$ \\
\hline
\end{tabular}

SO = sham operated; INT = infarcted not treated; C-hUCB = cryopreserved human umbilical cord blood; FhUCB = fresh human umbilical cord blood. âQRS between $0-90^{\circ}$ (left orientation) is characteristic of the normal heart, while right axis deviation $\left(90-180^{\circ}\right)$ is typical of infarcted hearts.

Table 2. Echocardiographic data of control, sham-operated and infarcted rats 3 weeks after the surgical procedure.

\begin{tabular}{lccccc}
\hline Parameters & Control $(\mathrm{N}=10)$ & SO $(\mathrm{N}=9)$ & INT $(\mathrm{N}=9)$ & C-hUCB $(\mathrm{N}=7)$ & F-hUCB $(\mathrm{N}=5)$ \\
\hline LVEDD $(\mathrm{mm})$ & $6.44 \pm 0.12$ & $6.78 \pm 0.40$ & $8.70 \pm 0.73^{*}$ & $8.9 \pm 0.60^{*}$ & $10.0 \pm 0.20^{*}$ \\
LVESD $(\mathrm{mm})$ & $3.24 \pm 0.22$ & $3.00 \pm 0.91$ & $6.70 \pm 0.09^{*}$ & $6.10 \pm 0.24^{*}$ & $8.90 \pm 0.60^{*}$ \\
EF $(\%)$ & $84.90 \pm 2.16$ & $89.50 \pm 10.89$ & $51.11 \pm 8.55^{*}$ & $48.60 \pm 10.47^{*}$ & $38.0 \pm 11.5^{*}$ \\
SF $(\%)$ & $49.40 \pm 3.01$ & $57.89 \pm 16.00$ & $23.08 \pm 4.92^{*}$ & $20.14 \pm 5.58^{*}$ & $20.4 \pm 10.4^{*}$ \\
SFA $(\%)$ & ND & $73.18 \pm 10.93$ & $29.09 \pm 6.11^{*}$ & $28.25 \pm 8.66^{*}$ & $33.34 \pm 10.36^{*}$ \\
\hline
\end{tabular}

Data are reported as means \pm SD. SO = sham operated; INT = infarcted not treated; C-hUCB = cryopreserved human umbilical cord blood; F-hUCB = fresh human umbilical cord blood; LVEDD = left ventricular end-diastolic dimensions; LVESD = left ventricular end-systolic dimensions; EF = ejection fraction; SF = shortening fraction; SFA = shortening fractional area; ND = not determined. ${ }^{*} \mathrm{P}<0.05$ compared to SO (one-way ANOVA).

Table 3. Left ventricular pressure measurements in sham-operated and infarcted unanesthetized rats 3 weeks after the surgical procedure.

\begin{tabular}{lccccc}
\hline Parameters & Control $(\mathrm{N}=9)$ & $\mathrm{SO}(\mathrm{N}=6)$ & $\mathrm{INT}(\mathrm{N}=7)$ & $\mathrm{C}-\mathrm{hUCB}(\mathrm{N}=6)$ & F-hUCB $(\mathrm{N}=4)$ \\
\hline $\mathrm{dP} / \mathrm{dT}+(\mathrm{mmHg} / \mathrm{s})$ & $7556.15 \pm 362.48$ & $8119 \pm 864$ & $5728 \pm 1477^{+}$ & $5484 \pm 875^{*}$ & $4585 \pm 955^{*}$ \\
$\mathrm{dP} / \mathrm{dT}-(\mathrm{mmHg} / \mathrm{s})$ & $-5897.20 \pm 245.11$ & $-6200 \pm 645$ & $-4277 \pm 838^{+}$ & $-4032 \pm 643^{*}$ & $-2862 \pm 590^{*}$ \\
$\mathrm{LVDP}(\mathrm{mmHg})$ & $129.20 \pm 4.26$ & $129.50 \pm 16.00$ & $89.88 \pm 12.67^{*}$ & $91.61 \pm 18.50^{*}$ & $83.13 \pm 6.90^{*}$ \\
\hline
\end{tabular}

Data are reported as means \pm SD. SO = sham operated; INT = infarcted not treated; C-hUCB = cryopreserved human umbilical cord blood; F-hUCB $=$ fresh human umbilical cord blood; $\mathrm{dP} / \mathrm{dT}+=$ index of left ventricular contractility; $\mathrm{dP} / \mathrm{dT}$ - = index of left ventricular relaxation; LVDP = left ventricular developed pressure. ${ }^{*} \mathrm{P}<$ 0.001 compared to SO; ${ }^{+} \mathrm{P}<0.01$ compared to SO (one-way ANOVA). 

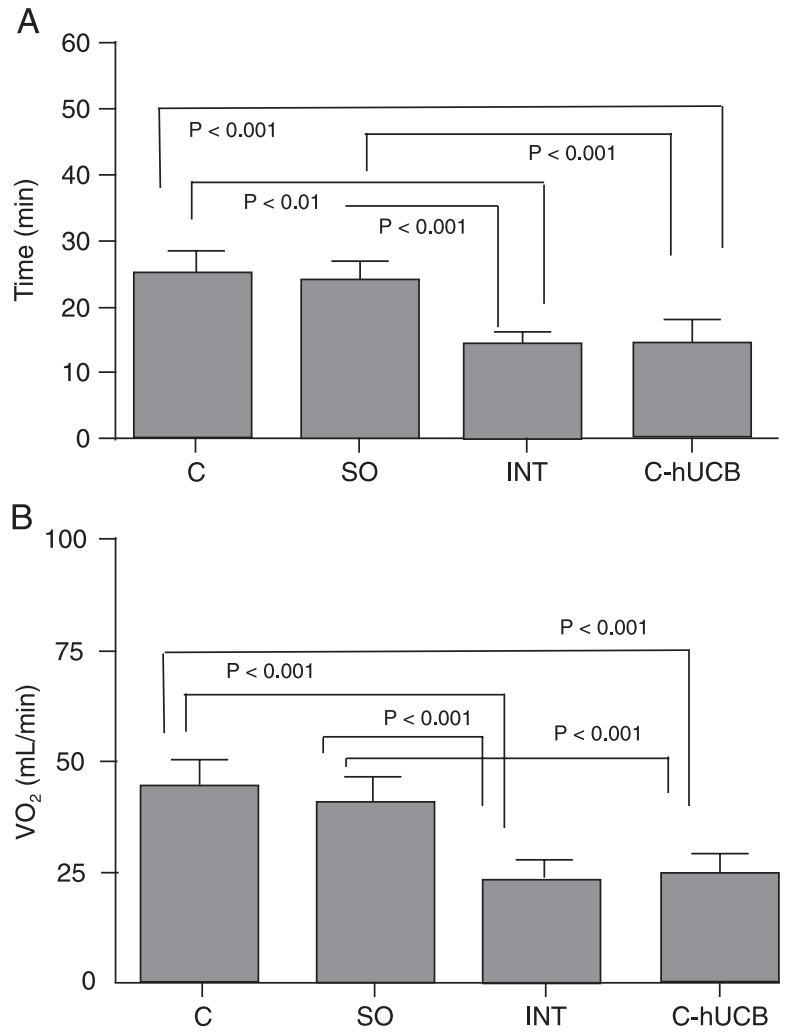

Figure 1. Evaluation of cardiopulmonary parameters 3 weeks after treatment. $A$, Total exercise time. $B$, Maximal oxygen consumption. Both parameters were significantly reduced in the $\mathrm{C}$ hUCB-treated group compared to the control and SO groups, and similar to the INT group. $\mathrm{C}=$ control; $\mathrm{SO}=$ sham operated; INT = infarcted not treated; C-hUCB = cryopreserved human umbilical cord blood. One-way ANOVA was used for these analyses.

three groups displayed values significantly different from the sham group.

\section{Cardiopulmonary exercise testing}

As shown in Figure 1, the total exercise time and $\mathrm{VO}_{2}$ max of the infarcted groups (INT and cryopreserved hUCB) were smaller when compared to sham animals. These parameters were not significantly different between cryopreserved hUCB-treated group and the untreated infarcted group.

\section{Microscopic analysis}

Histologic sections revealed the presence of Hoechststained nuclei in the left ventricle of fresh and cryopreserved hUCB-treated animals 3 weeks after cell injection (Figure 2). These cells were found mainly in section $B$ (see Histological procedures) at the border of the infarcted region and are mononuclear cells that were labeled before injection.

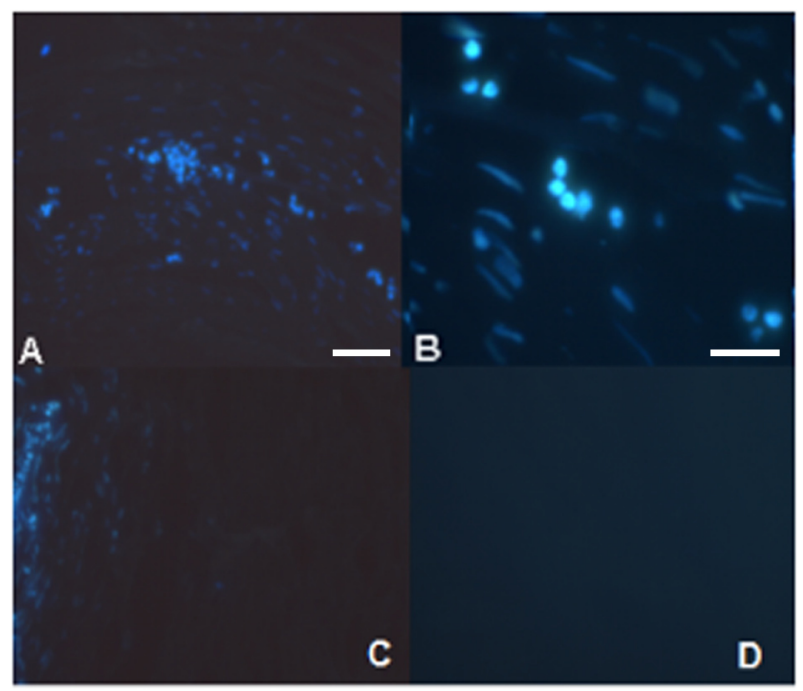

Figure 2. Human umbilical cord blood-stained cells in the infarcted myocardium. $A, B$, Note the presence of cells with nuclear labeling mainly in section $B$. These cells, with a round and flattened shape (B), were concentrated in an area of the section that macroscopically corresponds to the infarction border, where cells were injected. $C$, In one slice of the transition area, some labeled cells were also found. $D$, In the region away from infarction, no labeled cells were found. Magnification bars: $A$ and $C=$ $50 \mu \mathrm{m} ; \mathrm{B}$ and $\mathrm{D}=20 \mu \mathrm{m}$.

\section{Discussion}

Cell-based therapies have been proposed as an alternative treatment for many cardiovascular diseases. Bone marrow-derived cells from patients have been used in clinical trials to improve cardiac function in patients with acute $\mathrm{Ml}$ and chronic ischemic heart disease (for a review, see Ref. 17). However, the number and biological activity of mononuclear cells isolated from the bone marrow of older people or from patients with ischemic cardiomyopathy are significantly reduced (7). Based on these findings, several groups have investigated the application of hUCB in acute Ml models $(7,8,10-13)$.

In most of these studies, human cells have been injected into genetically immune incompetent animals or into pharmacologically immunosuppressed ones. However, even when using human cells in immunocompromised animals, results have been contradictory. At present, no more than fifteen original studies have used hUCB cells in models of MI. Given the importance that hUCB cells may have for therapeutic purposes and the contradictory results, the experiments reported here are relevant to the field, especially because, to our knowledge, we are the first to compare freshly isolated and cryopreserved mononuclear cells.

In infarcted NOD/SCID mice, CD $34^{+}$cells from hUCB have been shown to promote angiogenesis $(12,18)$ while 
mononuclear cells had no effect (18). In immunosuppressed rats, CD34+ and $\mathrm{CD}^{+} 33^{+}$cells from hUCB have been reported to improve LV function after acute MI $(11,13)$.

Henning et al. (8) used immunocompetent rats without immune suppression and reported reduction in infarct size and improvement in ventricular function after hUCB mononuclear cell injection $(7,8)$. Similar results have been reported by Wu et al. (10) using mesenchymal stem cells from hUCB in infarcted rat models without immune suppression. This result is astonishing from the immunological point of view and may indicate that the use of allogeneic cord blood could be a therapeutic alternative for cardiac patients, rendering hUCB even more attractive for clinical use. Unfortunately our results do not confirm these findings. We have analyzed possible differences in the experimental models. First, since we tested freshly isolated and cryopreserved cells, differences in cell handling cannot explain the different results obtained. The number of cells injected also does not seem to justify the discrepancy in results; we injected more cells than most other groups. Henning et al. (8) have reported a dose-dependent effect of intramyocardially injected hUCB cells in their rat model, with the highest dose used $\left(4 \times 10^{6}\right.$ cells) being the most effective. Cell processing differences are unlikely to account for the differences in results, and since the only functional test to which cells were subjected after processing was exactly their effect in the infarction

\section{References}

1. Litwin SE, Katz SE, Morgan JP, Douglas PS. Serial echocardiographic assessment of left ventricular geometry and function after large myocardial infarction in the rat. Circulation 1994; 89: 345-354

2. Chiu RC, Zibaitis A, Kao RL. Cellular cardiomyoplasty: myocardial regeneration with satellite cell implantation. Ann Thorac Surg 1995; 60: 12-18.

3. Dimmeler S, Zeiher AM, Schneider MD. Unchain my heart: the scientific foundations of cardiac repair. J Clin Invest 2005; 115: 572-583.

4. Scorsin M, Hagege A, Vilquin JT, Fiszman M, Marotte F, Samuel JL, et al. Comparison of the effects of fetal cardiomyocyte and skeletal myoblast transplantation on postinfarction left ventricular function. J Thorac Cardiovasc Surg 2000; 119: 1169-1175.

5. Menasche P, Hagege AA, Scorsin M, Pouzet B, Desnos M, Duboc D, et al. Myoblast transplantation for heart failure. Lancet 2001; 357: 279-280.

6. Heeschen C, Lehmann R, Honold J, Assmus B, Aicher A, Walter $\mathrm{DH}$, et al. Profoundly reduced neovascularization capacity of bone marrow mononuclear cells derived from patients with chronic ischemic heart disease. Circulation 2004; 109: 1615-1622.

7. Dimmeler S, Leri A. Aging and disease as modifiers of efficacy of cell therapy. Circ Res 2008; 102: 1319-1330.

8. Henning RJ, Abu-Ali H, Balis JU, Morgan MB, Willing AE, Sanberg PR. Human umbilical cord blood mononuclear cells for the treatment of acute myocardial infarction. Cell model (as opposed to colony forming or migration assays), and cell viability after processing was similar in most studies, it is difficult to attribute to cell processing the different results without additional comparisons of functional capabilities. The content of CD34 ${ }^{+}$cells in the mononuclear fraction was similar in all models, ranging from 1 to $3 \%$. One possible difference is that in our model we determined echocardiographic parameters immediately after infarction, guaranteeing that all infarcted animals started out from the same baseline value and thus validating comparisons after cell or placebo injection.

The results obtained from experimental models using larger animals have also been contradictory. While Kim et al. (19) reported improvement in ventricular function after intramyocardial hUCB cell injection in immunosuppressed infarcted pigs, Moelker et al. (20) found no evidence for cardiac improvement in the same animal model, using the same cell type but using the intracoronary injection route.

In conclusion, the mononuclear fraction of cord blood is not a suitable source for xenogenic cardiac cell therapy in non-immunosuppressed animals.

\section{Acknowledgments}

Research supported by CAPES, CNPq, FAPERJ, and Ministério da Saúde.
Transplant 2004; 13: 729-739.

9. Henning RJ, Burgos JD, Vasko M, Alvarado F, Sanberg CD, Sanberg PR, et al. Human cord blood cells and myocardial infarction: effect of dose and route of administration on infarct size. Cell Transplant 2007; 16: 907-917.

10. Wu KH, Yang SG, Zhou B, Du WT, Gu DS, Liu PX, et al. Human umbilical cord derived stem cells for the injured heart. Med Hypotheses 2007; 68: 94-97.

11. Hirata $Y$, Sata M, Motomura N, Takanashi M, Suematsu $Y$, Ono M, et al. Human umbilical cord blood cells improve cardiac function after myocardial infarction. Biochem Biophys Res Commun 2005; 327: 609-614.

12. Ma N, Stamm C, Kaminski A, Li W, Kleine HD, Muller-Hilke $B$, et al. Human cord blood cells induce angiogenesis following myocardial infarction in NOD/scid-mice. Cardiovasc Res 2005; 66: 45-54.

13. Leor J, Guetta E, Feinberg MS, Galski H, Bar I, Holbova $\mathrm{R}$, et al. Human umbilical cord blood-derived $\mathrm{CD} 133^{+}$cells enhance function and repair of the infarcted myocardium. Stem Cells 2006; 24: 772-780.

14. Olivares EL, Ribeiro VP, Werneck de Castro JP, Ribeiro KC, Mattos EC, Goldenberg RC, et al. Bone marrow stromal cells improve cardiac performance in healed infarcted rat hearts. Am J Physiol Heart Circ Physiol 2004; 287: H464-H470.

15. Miranda A, Costa-e-Sousa RH, Werneck-de-Castro JP, Mattos EC, Olivares EL, Ribeiro VP, et al. Time course of echocardiographic and electrocardiographic parameters in myocardial infarct in rats. An Acad Bras Cienc 2007; 79: 
639-648.

16. Werneck-de-Castro JP, Costa-e-Sousa RH, de Oliveira PF, Pinho-Ribeiro V, Mello DB, Pecanha R, et al. G-CSF does not improve systolic function in a rat model of acute myocardial infarction. Basic Res Cardiol 2006; 101: 494-501.

17. Abdel-Latif A, Bolli R, Tleyjeh IM, Montori VM, Perin EC, Hornung $\mathrm{CA}$, et al. Adult bone marrow-derived cells for cardiac repair: a systematic review and meta-analysis. Arch Intern Med 2007; 167: 989-997.

18. Botta R, Gao E, Stassi G, Bonci D, Pelosi E, Zwas D, et al. Heart infarct in NOD-SCID mice: therapeutic vasculogenesis by transplantation of human CD34+ cells and low dose
CD34+KDR+ cells. FASEB J 2004; 18: 1392-1394.

19. Kim BO, Tian $\mathrm{H}$, Prasongsukarn $\mathrm{K}, \mathrm{Wu} J$, Angoulvant $\mathrm{D}$, Wnendt $\mathrm{S}$, et al. Cell transplantation improves ventricular function after a myocardial infarction: a preclinical study of human unrestricted somatic stem cells in a porcine model. Circulation 2005; 112: I-96-I-104.

20. Moelker AD, Baks T, Wever KM, Spitskovsky D, Wielopolski $\mathrm{PA}$, van Beusekom HM, et al. Intracoronary delivery of umbilical cord blood derived unrestricted somatic stem cells is not suitable to improve LV function after myocardial infarction in swine. J Mol Cell Cardiol 2007; 42: 735-745. 